\title{
Description of Nosocomial Infection Prevention Practices by Anesthesiologists in a University Hospital
}

\author{
Daniel Kishi ${ }^{1}$, Rogério Luiz da Rocha Videira, TSA ${ }^{2}$
}

\begin{abstract}
Summary: Kishi D; Videira RLR - Description of Nosocomial Infection Prevention Practices by Anesthesiologists in a University Hospital.
Background and objectives: Anesthesiologists play an important role in the prevention of nosocomial infections. In anesthetic practice, physiologic barriers are routinely breached, allowing patient contamination with microorganisms and the consequent development of infection. The lack of adhesion to recommended practices can facilitate transmission of microorganisms. It is important to describe prophylactic practices of anesthesiarelated nosocomial infections performed by anesthesiologists.
\end{abstract}

Methods: Structured questionnaires were distributed to be answered voluntarily and anonymously by anesthesiologists.

Results: Among 112 anesthesiologists, $75 \%$ answered the questionnaire. Surgical mask is used by $95.2 \%$ of anesthesiologists, $96.3 \%$ wear gloves frequently, $98.9 \%$ wear sterile gloves for neuraxial block, $91.3 \%$ use sterile technique for central venous puncture, $95.1 \%$ wash their hands between cases, $91.6 \%$ try to maintain the endotracheal tube sterile, $96.3 \%$ discard the prefilled propofol syringe at the end of each anesthesia, $30 \%$ clean the vials before using it in the neuraxial blocks, and $19.8 \%$ clean the vials before intravenous use.

Conclusions: Respondents showed good adhesion to practices of nosocomial infection prophylaxis and to improve them educational multidisciplinary campaigns are necessary.

Keywords: Infection Control; Universal Precautions; Asepsis; Anesthesia.

\section{INTRODUCTION}

Anesthesiologists play an important role in the prevention of cedures that breach physiologic barriers, such as tracheal intubation, venous access, or neuraxial blocks are routinely performed allowing contamination of patients with microorganisms and development of infection. Non-adhesion to recommended practices can facilitate transmission of microorganis$\mathrm{ms}$ from the anesthesiologist to the patient, from the patient to the anesthesiologist, and between patients ${ }^{1}$.

Hygiene practices of professionals, adequate cleaning of equipment, and adequate execution of invasive procedures are among important aspects for the reduction of the risk of transmission of infections ${ }^{2}$.

Hygiene practices related to the anesthetic procedures have been investigated in different countries, such as United States, United Kingdom, New Zealand, and France ${ }^{3-6}$. nosocomial infections. In anesthetic practice, invasive pro-

\section{METHODS}

After approval by the Institutional Ethics Committee of the Hospital das Clínicas of Faculdade de Medicine of Universidade de São Paulo, questionnaires were distributed to anesthesiologists who work in the operating suite of the Instituto Central of that hospital.

The questionnaire was translated and freely adapted from prior studies on prevention of perioperative infections $s^{4,5}$ and it was voluntarily and anonymously answered by anesthesiologists (Questionnaire).

One hundred and twelve questionnaires were distributed to anesthesiologists between September 2007 and August 2008.

Anesthesiologists from the Anesthesiology Division of the Hospital das Clínicas de São Paulo were included in this study as, a convenient, non-random population.

Exclusion criteria were: 1. Anesthesiologists who are not routinely involved in intraoperative care of surgeries conducted at the operating suite; 2 . Refusal to answer the questionnaire or to sign the informed consent.

\section{RESULTS}

de São Paulo (USP) - Study performed at Hospital das Clínicas (HC) of Faculdade de Medicina of USP (FM/USP), Brazil.

1. Anesthesiologist

2. Anesthesiologist of HC da FM/USP

Submitted on July 13, 2010

Approved on September 9, 2010.

Correspondence to:

Dr. Daniel Kishi

Rua Serafim Dias Machado no 171

Vila Maria

12209-240 - São Jose dos Campos, SP, Brazil

E-mail:dk3www@yahoo.com
Out of the 112 questionnaires distributed, 84 were answered, which indicates that $75 \%$ of the professionals participated in the study. Routine use of eye protection was reported by $21.2 \%$ of anesthesiologists, while $95.2 \%$ always or frequently wear a surgical mask; $96.3 \%$ wear general procedure gloves, while $84.1 \%$ use them for venous cannulation; $98.8 \%$ wear sterile gloves for the neuraxial block, and $87 \%$ wear them for peripheral nerve blocks. Sterile technique including hand wa- 
Table I - Amount and Percentage of Answers of the Questionnaire $(n=84)$

\begin{tabular}{|c|c|c|c|c|}
\hline & Never & Rare & Always & Freq \\
\hline & $\mathrm{N}$ & $\%$ & $\mathrm{~N}$ & $\%$ \\
\hline Do you wear goggles? & 62 & 73.8 & 22 & 26.2 \\
\hline Do you wear gloves? & 3 & 3.7 & 79 & 96.3 \\
\hline Procedure gloves - Venous cannulation & 13 & 15.9 & 69 & 84.1 \\
\hline Sterile gloves - Neuraxial blocks & 1 & 1.2 & 80 & 98.8 \\
\hline $\begin{array}{l}\text { Do you wash your hands and wear a cap, mask, sterile } \\
\text { gown and gloves for central venous access? }\end{array}$ & 7 & 8.8 & 73 & 91.3 \\
\hline Do you wash your hands between cases? & 4 & 4.9 & 78 & 95.1 \\
\hline Do you wash your hands before neuraxial blocks? & 21 & 25.9 & 60 & 74.1 \\
\hline Do you wash your hands after removing your gloves? & 9 & 11.0 & 73 & 89.0 \\
\hline Do you refill the prefilled propofol syringe/diprofusor for the same patient? & 39 & 47.6 & 43 & 52.4 \\
\hline Do you sue a three-way stopcock for IV injection of drugs? & 3 & 3.7 & 79 & 96.3 \\
\hline \multicolumn{5}{|l|}{ Do you clean the vials of drugs with alcohol before using them? } \\
\hline Intravenous drugs & 65 & 80.2 & 16 & 19.8 \\
\hline Neuraxial drugs & 56 & 70.0 & 24 & 30.0 \\
\hline
\end{tabular}

shing, mask, headwear, sterile gown, and sterile glove was reported by $91.3 \%$ of anesthesiologist (Table I).

Ninety-five per cent of anesthesiologists wash their hands between cases, $89 \%$ wash their hands when removing the gloves, and $74.1 \%$ wash their hands before a neuraxial block.

The endotracheal tube is maintained sterile by $91.6 \%$ of anesthesiologists, and $95.1 \%$ change the filter of the ventilation system between patients.

Prefilled propofol syringe was discarded at the end of each anesthesia by $98.8 \%$ of anesthesiologists; however, $52.4 \%$ refill the propofol syringe for the same patient.

A three-way stopcock is used for intravenous infusion of drugs by $96.3 \%$; however, only $30 \%$ reported cleaning vials of drugs with alcohol for use in the neuraxial blocks, while $19.8 \%$ clean vials before intravenous administration.

\section{DISCUSSION}

Compared to other studies, such as that of Tait et al. in the United States ${ }^{3}$, with $44 \%$ of participation, El Mikatti et al. in the United Kingdom ${ }^{4}$, with $68 \%$, and Ryan et al. in New Zealand ${ }^{5}$, with $61 \%$, the participation of anesthesiologists in the present study $(75 \%)$ can be considered favorably.

The data presented here shows good adhesion to practices of prophylaxis of nosocomial infections, which can be favorably compared to studies in other countries.

In this study, $73.8 \%$ of those interviewed never or rarely wear protective goggles. The only study in which this item was mentioned, performed by Ryan et al. ${ }^{5}$ in New Zealand
(NZ), reported similar rates, 63\%. Regarding the mask, we observed a proportion similar to the American study of Tait et al. ${ }^{3}(94.9 \%)$ and higher than that of the United Kingdom (UK $-68.3 \%)^{4}$ and New Zealand $(59.5 \%)^{5}$. A higher proportion of anesthesiologists reported wearing gloves (96.3\%) than that of the studies of Tait et al. ${ }^{3}$ (USA - 86.3\%), El Mikatti et al. ${ }^{4}$ (UK - 54\%), and Ryan et al. ${ }^{5}$ (NZ - 84.2\%). Regarding neuraxial block, a similar proportion to that of the study of Ryan et al. ${ }^{5}$ (NZ), i.e., $98.8 \%$ vs. $99.3 \%$, reported wearing sterile gloves, indicating a well established practice in both countries, but this data is not available in the other studies. Adhesion in our institution (91.3\%) to the sterile technique, with sterile cap, mask, gloves, and gown for central venous access was lower than that reported by Tait et al. ${ }^{3}$ (USA), but higher than that reported by El Mikatti et al. ${ }^{4}$ (UK) and Ryan et al. ${ }^{5}$ (NZ), with $70.4 \%$ and $70 \%$, respectively (Table II).

Washing hands between cases, a simple procedure that can prevent transmission of microorganisms with the best cost/benefit relationship 7 , was reported by $95.1 \%$ of anesthesiologists in the present study, compared to $83.9 \%$, in the study of El Mikatti et al. ${ }^{4}$ (UK), and $93.7 \%$, in the study of Ryan et al. ${ }^{5}$ (NZ). Adhesion to this practice is lower before neuraxial blocks $(74.1 \%)$; despite this, it represented more than double of that observed by Videira et al. ${ }^{7}(32 \%)$ in a prior study performed in Brazil. According to a recent recommendation of the ASA (American Society of Anesthesiologists), before a neuraxial block, one should wash his/her hands, wear sterile gloves, cap, and mask covering the mouth and nose, besides using individual packages in skin preparation, and remove all jewelry; however, the recommendation of 
wearing a sterile gown and changing masks before a new case is uncertain ${ }^{8}$.

The results suggest effective care with airways contamination, since $91.6 \%$ of anesthesiologists try to maintain the endotracheal tube sterile, and $95.1 \%$ change the filter of the ventilation system between patients. This care was considerable lower in the study of El Mikatti et al. ${ }^{4}$ (UK $-7.2 \%$ ), while in the study of Ryan et al. ${ }^{5}$ (NZ), 97.1\% reported this change. This suggests an improvement in practice in the last decade, although the places of the studies were different (Brazil, UK ${ }^{4}$, and NZ ${ }^{5}$ ), but this item was not analyzed in the American study.

Similar to the study of Ryan et al. ${ }^{5}$ (NZ), the prefilled propofol syringe was not used in different patients, revealing an adequate practice; however, more than half of those interviewed frequently refill the syringe for the same patient, but the studies undertaken in the USA ${ }^{3}$ and UK ${ }^{4}$ did not report this data.

Although Hemingway et al. ${ }^{9}$ have shown that cleaning the exterior of vials with alcohol can reduce contamination of the contents, the majority of anesthesiologists does not clean vials before using them, which increases the risks of drug contamination.

Adhesion to prophylactic practices of nosocomial infection reported in the present study was comparatively better than that observed in prior studies.

Some aspects, such as cleaning drug vials with alcohol, are still well below which is desired, indicating that this practice should be stimulated.

To improve hygiene practices, it is possible to suggest placement of signs and charts in anesthesiologist work stations, besides a procedures manual, available in electronic form and as an easy access booklet. Besides, manufactures of drugs used in our specialty could stimulate good clinical practice by printing on packages the recommendation of cleaning them before using them or adopting a sterile package for drugs used in neuraxial blocks.

Table II - Summary of the Main Data of the Studies on Hygiene Practices and Anesthesia (in percentage)

\begin{tabular}{|c|c|c|c|c|}
\hline & $\begin{array}{l}\text { Brazil } \\
2009\end{array}$ & $\begin{array}{c}\text { New } \\
\text { Zealand } \\
2006\end{array}$ & $\begin{array}{l}\text { United } \\
\text { Kingdom } \\
1999\end{array}$ & $\begin{array}{l}\text { USA } \\
1995\end{array}$ \\
\hline Goggles & 73.8 & 63 & - & - \\
\hline Mask & 95.2 & 59.5 & 68.3 & 94.9 \\
\hline Gloves & 96.3 & 84.2 & 54 & 86.3 \\
\hline $\begin{array}{l}\text { Sterile gloves for } \\
\text { neuraxial blocks }\end{array}$ & 98.8 & 99.3 & - & - \\
\hline $\begin{array}{l}\text { Central venous access - } \\
\text { Sterile technique }\end{array}$ & 91.3 & 70 & 70.4 & 97.5 \\
\hline $\begin{array}{l}\text { Wash hands between } \\
\text { cases }\end{array}$ & 95.1 & 93.7 & 83.9 & - \\
\hline $\begin{array}{l}\text { Change the filter of the } \\
\text { ventilation system }\end{array}$ & 95.1 & 97.1 & 7.2 & - \\
\hline
\end{tabular}

Does not reuse the prefilled propofol syringe in different patients $98.8 \quad 97.8$

\section{Questionnaire}

$0.1)$ Year of graduation from medical school:

$0.2)$ Title of anesthesiologist

a) Yes:

b) No:

0.3) Master's Degree

a) Yes:

b) No:

0.4) PhD

a) Yes:

b) No: $\square$

1. How long have you been practicing anesthesiology?
a) 0 to 5 years
b) 5 to 10 years
c) 10 to 15 years
d) $>15$ years

2. Do you wear goggles?
a) Never
b) Rarely
c) Frequently
d) Always

3. Why do you do not wear it frequently?
a) It is not available in the operating room
b) I wear glasses
c) fogging of the lenses gets in the way
d) It depends on the surgery
e) It does not fit on my face
f) Others:

4. Do you a wear mask in the operating room?
a) Never
b) Rarely
c) Frequently
d) Always

Surgical mask a) Never $\begin{array}{llll}\text { b) Rarely } & \text { c) Frequently } & \text { d) Always }\end{array}$

\begin{tabular}{|c|c|c|c|c|c|}
\hline 4.1) & $\begin{array}{l}\text { Tracheal } \\
\text { intubation }\end{array}$ & $\square$ & $\square$ & $\square$ & $\square$ \\
\hline 4.2$)$ & Extubation & $\square$ & $\square$ & $\square$ & $\square$ \\
\hline 4.3) & Neuraxial blocks & $\square$ & $\square$ & $\square$ & $\square$ \\
\hline 4.4) & Peripheral blocks & $\square$ & $\square$ & $\square$ & $\square$ \\
\hline 4.5) & $\begin{array}{l}\text { Venous } \\
\text { cannulation }\end{array}$ & $\square$ & $\square$ & & $\square$ \\
\hline 4.6) & $\begin{array}{l}\text { Central venous } \\
\text { access }\end{array}$ & $\square$ & $\square$ & D & $\square$ \\
\hline 4.7) & $\mathrm{BPi}$ & $\square$ & $\square$ & $\square$ & $\square$ \\
\hline
\end{tabular}

5. In which situations do you wear q mask covering your nose? (you can chose more than one answer)
a) Never
b) Whenever I am in the operating room
c) During tracheal intubation
d) Whenever performing neuraxial blocks
e) Whenever performing peripheral blocks
f) Whenever performing central venous access
g) Whenever the surgeon asks me to

6. Do you wear gloves?
a) Never
b) Rarely
c) Frequently
d) Always 
6.1) Do you change gloves between cases? Yes $\square$ No $\square$

\begin{tabular}{|c|c|c|c|c|}
\hline Procedure gloves & a) Never & b) Rarely & c) Frequently & d) Always \\
\hline $\begin{array}{l}\text { 6.2.1) Tracheal } \\
\text { intubation }\end{array}$ & $\square$ & $\square$ & $\square$ & $\square$ \\
\hline 6.2.2) Extubation & $\square$ & $\square$ & $\square$ & $\square$ \\
\hline 6.2.3) Neuraxial blocks & $\square$ & $\square$ & $\square$ & $\square$ \\
\hline 6.2.4) Peripheral blocks & $\square$ & $\square$ & $\square$ & $\square$ \\
\hline $\begin{array}{l}\text { 6.2.5) Venous } \\
\text { cannulation }\end{array}$ & $\square$ & $\square$ & $\square$ & $\square$ \\
\hline $\begin{array}{l}\text { 6.2.6) Central venous } \\
\text { Access }\end{array}$ & $\square$ & $\square$ & $\square$ & $\square$ \\
\hline 6.2.7) BPi & $\square$ & $\square$ & $\square$ & $\square$ \\
\hline Sterile gloves & a) Never & b) Rarely & c) Frequently & d) Always \\
\hline $\begin{array}{l}\text { 6.3.1) Tracheal } \\
\text { intubation }\end{array}$ & $\square$ & $\square$ & $\square$ & $\square$ \\
\hline 6.3.2) Extubation & $\square$ & $\square$ & $\square$ & $\square$ \\
\hline 6.3.3) Neuraxial blocks & $\square$ & $\square$ & $\square$ & $\square$ \\
\hline 6.3.4) Peripheral blocks & $\square$ & $\square$ & $\square$ & $\square$ \\
\hline $\begin{array}{l}\text { 6.3.5) Venous } \\
\text { cannulation }\end{array}$ & $\square$ & $\square$ & $\square$ & $\square$ \\
\hline $\begin{array}{l}\text { 6.3.6) Central venous } \\
\text { Access }\end{array}$ & $\square$ & $\square$ & $\square$ & $\square$ \\
\hline 6.3.7) BPi & $\square$ & $\square$ & $\square$ & $\square$ \\
\hline
\end{tabular}

7. Do you use sterile technique, i.e., washing your hands, wearing a $\mathrm{c}^{\mathrm{TM}} \mathrm{ap}$, mask, sterile gown, and sterile gloves, for central venous puncture?
a) Never
b) Rarely
c) Frequently
d) Always

8. Is alcohol gel available for disinfection of the hands in the OR?
a) Yes
b) No
c) I do not know

\begin{tabular}{|c|c|c|c|c|c|}
\hline \multicolumn{2}{|c|}{ Wash hands } & \multirow{2}{*}{$\begin{array}{c}\text { a) Never } \\
\square\end{array}$} & \multirow{2}{*}{$\begin{array}{c}\text { b) Rarely } \\
\square\end{array}$} & \multirow{2}{*}{$\begin{array}{c}\text { c) Frequently } \\
\qquad\end{array}$} & \multirow{2}{*}{$\begin{array}{c}\text { d) Always } \\
\square\end{array}$} \\
\hline 8.1) & $\begin{array}{l}\text { When beginning } \\
\text { your day at the } \\
\text { operating room }\end{array}$ & & & & \\
\hline 8.2) & Between cases & $\square$ & $\square$ & $\square$ & $\square$ \\
\hline 8.3) & $\begin{array}{l}\text { Upon getting in } \\
\text { close contact } \\
\text { with secretions/ } \\
\text { blood }\end{array}$ & $\square$ & $\square$ & $\square$ & $\square$ \\
\hline 8.4) & $\begin{array}{l}\text { Before inducing } \\
\text { general } \\
\text { anesthesia }\end{array}$ & $\square$ & $\square$ & $\square$ & $\square$ \\
\hline 8.5) & Neuraxial blocks & $\square$ & $\square$ & $\square$ & $\square$ \\
\hline 8.6) & Peripheral blocks & $\square$ & $\square$ & $\square$ & $\square$ \\
\hline 8.7) & $\begin{array}{l}\text { Venous } \\
\text { cannulation }\end{array}$ & $\square$ & $\square$ & $\square$ & $\square$ \\
\hline 8.8) & $\begin{array}{l}\text { Central venous } \\
\text { access }\end{array}$ & $\square$ & $\square$ & $\square$ & $\square$ \\
\hline 8.9) & $\begin{array}{l}\text { Upon removing } \\
\text { the gloves }\end{array}$ & $\square$ & $\square$ & $\square$ & $\square$ \\
\hline
\end{tabular}

9. Do you try to maintain the tracheal intubation tube sterile?
a) Never
b) Rarely
c) Frequently
d) Always

10.Do you change the ventilation circuit:
a) After each patient
b) Only after infected or high-risk patients
c) At the end of the day
d) Both b and c
e) Others:. .......
f) I do not know

11.Do you change the filter in the ventilation system between patients?
a) Never
b) Rarely
c) Frequently
d) Always

12.Laryngoscope blades are sterilized:
a) After each patient
b) Only after infected or high risk patients
c) At the end of the day
d) Both b e c
e) Others:. . . . . .
f) I do not know

13. What type of processing is done with the laryngoscope blade between patients?
a) Wash with water and soap
b) Clean with alcohol
c) High-level disinfection
d) Sterilization
e) Others:. . . . . .
f) I do not know

14.Is a disposable laryngoscope blade available?
a) Yes
b) $\mathrm{No}$
c) I do not know

15.After the anesthesia, the anesthesia equipment is cleaned with disinfection/germicide agent?
a) Never
b) Rarely
c) Frequently
d) Always
e) I do not know

16. Do you prepare syringes before beginning the day/ period to be used in several patients?
a) Yes
b) No

17.Do you use a propofol syringe/diprofusor to administer medications to more than one patient?
a) Never
b) Rarely
c) Frequently
d) Always

18.Do you refill the propofol syringe/diprofusor for the same patient?
a) Never
b) Rarely
c) Frequently
d) Always 
19.If yes, why do you refill the propofol syringe/ diprofusor for the same patient?
a) Price of the syringe
b) Limitations of the number of syringes of "Diprivan PFS"
c) Other:

20. Do you use a syringe to administer medications to more than one patient? (except the diprofusor)
a) Never
b) Rarely
c) Frequently
d) Always

21.Do you use the three-way stopcock to administer drugs?
a) Never
b) Rarely
c) Frequently
d) Always

22. Do you clean the vials of medications with alcohol before using them?

\begin{tabular}{|c|c|c|c|c|c|}
\hline \multicolumn{2}{|c|}{ Sterile gloves } & \multirow{2}{*}{$\begin{array}{c}\text { a) Never } \\
\square\end{array}$} & \multirow{2}{*}{$\begin{array}{c}\text { b) Rarely } \\
\square\end{array}$} & \multirow{2}{*}{$\begin{array}{c}\text { c) Frequently } \\
\square\end{array}$} & \multirow{2}{*}{$\begin{array}{c}\text { d) Always } \\
\square\end{array}$} \\
\hline 22.1) & $\begin{array}{l}\text { Intravenous } \\
\text { medications }\end{array}$ & & & & \\
\hline 22.2) & $\begin{array}{l}\text { Neuraxial block } \\
\text { drugs }\end{array}$ & $\square$ & $\square$ & $\square$ & $\square$ \\
\hline 22.3) & $\begin{array}{l}\text { Peripheral blocks } \\
\text { drugs }\end{array}$ & $\square$ & $\square$ & $\square$ & $\square$ \\
\hline
\end{tabular}

23.Did you have a needle stick-cutting accident with blood in the last 12 months?
a) Yes
b) No. How many times?

24.Did you notify this accident?
a) Yes
b) No

24.1. If not, why?

I. I did not consider the accident to be important

II. I did not have time

III. The notification does not make a difference

IV. I collected the exams of the patient (HIV, HbsAg, HepC)

V. Others

25. Have you been vaccinated against hepatitis $B$ ?
a) Yes
b) No

26.Do you know your immune status against hepatitis B?
a) I do not know
b) Protected against hepatitis $B$
c) Not protected against hepatitis B
d) Carrier of hepatitis B
e) I would rather not answer this question

27.Do you recap the needle after collecting blood? (patient contact)
a) Never
b) Rarely
c) Frequently
d) Always

28. Do you recap the needle after applying medications through the infusion tubing?

(without patient contact)

a) Never

b) Rarely

c) Frequently

d) Always

29.Do you usually work when you have:

$\begin{array}{llll}\text { a) Never } & \text { b) Rarely } & \text { c) Frequently } & \text { d) Always }\end{array}$

29.1) Respiratory infection (cold, flu, etc)

29.2) Gastrointestinal infection?

29.3) Herpes?

29.4) Psoriasis / dermatitis?

29.5) Other:

...............

$\ldots \ldots \ldots \ldots \ldots$

30.Do you change your conducts if you know the patient is HIV positive?

$\square$ Yes $\square$ No

Comments: . . .

31.Do you change your conducts if you know the patients has hepatitis $\mathrm{B}$ or $\mathrm{C}$ ?

$\square$ Yes $\square$ No

Comments: . .

32. On a scale from 0 (none) to 10 (significantly), how do you consider the transmission potential of infectious agents of the anesthetic procedure for the patient?

\begin{tabular}{|l|l|l|l|l|l|l|l|l|l|l|}
\hline 0 & 1 & 2 & 3 & 4 & 5 & 6 & 7 & 8 & 9 & 10 \\
\hline
\end{tabular}

33. On a scale of 0 (none) to 10 (significant), how do you consider the transmission potential of infectious agents of the anesthetic procedure for the anesthesiologist?

\begin{tabular}{|l|l|l|l|l|l|l|l|l|l|l|}
\hline 0 & 1 & 2 & 3 & 4 & 5 & 6 & 7 & 8 & 9 & 10 \\
\hline
\end{tabular}

34.Do you have access to the nosocomial infection control manual? $\square$ Yes $\square$ No

35. Have you read the nosocomial infection control manual? $\square$ Yes $\square$ No

36. How would you grade the role of the nosocomial infection control commission in the operating room?

\begin{tabular}{|l|l|l|l|l|l|l|l|l|l|l|}
\hline 0 & 1 & 2 & 3 & 4 & 5 & 6 & 7 & 8 & 9 & 10 \\
\hline
\end{tabular}

37.Do you have any suggestions to improve patient and physician safety regarding transmission of infections during the anesthetic procedure?

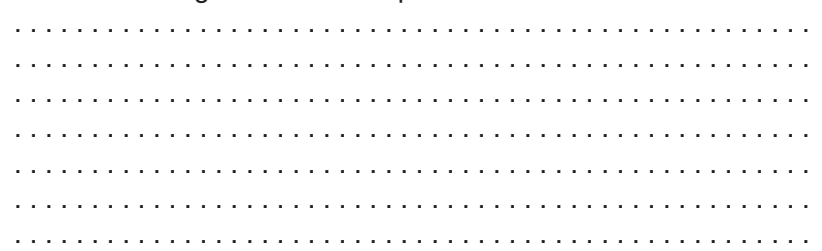

Thank you for answering this questionnaire. 